\title{
Sobre os métodos da pesquisa em nutrição
}

Ao inaugurar uma Seção Temática, em dezembro de 2006', publicando as reflexões sobre o I Fórum de Coordenadores de Pós-Graduação em Nutrição, a Revista de Nutrição ratificou o propósito de se apresentar como um espaço para a veiculação da produção científica qualificada, gerada pelos programas de Pós-Graduação em Nutrição no Brasil.

O Fórum de Coordenadores de Programas de Pós-Graduação em Nutrição foi constituído em junho de 2006, na cidade de Salvador, por iniciativa do Programa de Pós-Graduação em Nutrição da Universidade Federal do Rio de Janeiro, em parceria com o Programa de Alimentação, Nutrição e Saúde da Universidade Federal da Bahia ${ }^{2,3}$.

Como conseqüência desse movimento inicial, foram realizados dois outros encontros nacionais: em Recife, em 2007, organizado pelo Programa de Pós-Graduação em Nutrição da Universidade Federal de Pernambuco ${ }^{4}$, e em 2008, em Brasília, promovido pelos Programas de Nutrição da Universidade de Brasília e da Universidade Federal de Viçosa.

O histórico encontro de coordenadores abordou diversos assuntos atinentes ao processo de avaliação do sistema de Pós-Graduação Nacional, e em especial à qualidade e à relevância do conhecimento científico produzido no campo da Alimentação e Nutrição, escopo dos programas de Pós-Graduação que conformam a área. Em linhas gerais, o Fórum se propôs a promover a integração dos Programas de Pós-Graduação em Nutrição incluindo a organização dos mesmos em uma associação, para o fortalecimento político da área².

Uma estratégia que foi amplamente debatida diz respeito à busca de qualificação metodológica dos projetos de pesquisa, requisito básico para a afirmação da produção científica no plano nacional e internacional, e para consolidar a formação de mestres e doutores. Disso resultou a proposição de um Fórum para discutir questões de método concernentes à pesquisa em Nutrição².

Nessa direção, foi organizado o I Seminário de Métodos na Pós-Graduação em Nutrição, aninhado às atividades do IX Congresso Brasileiro de Nutrição, realizado pela Sociedade Brasileira de Alimentação e Nutrição (SBAN), em outubro de 2007. O seminário teve duração de 12 horas e as atividades foram distribuídas em duas conferências e quatro mesas redondas, totalizando 10 apresentações de pesquisadores renomados das quatro principais áreas: epidemiologia nutricional, ciência e tecnologia dos alimentos, nutrição clínica e bioquímica nutricional.

O teor das abordagens daquele evento e a adesão dos congressistas motivaram a Revista de Nutrição, mais uma vez, a disponibilizar os principais conteúdos das exposições do I Seminário de Métodos na Pós-Graduação em Nutrição em duas Seções Temáticas dedicadas ao assunto.

Com uma história recente, que remonta aos anos 40, o desenvolvimento do campo da Nutrição no Brasil ${ }^{5,6}$ tem experimentado avanços significativos. O resultado desse percurso se percebe pela observação do crescimento do número de publicações relativas à nutrição e pela ampliação de seu 
espectro no cenário mundial. A recente indexação da Revista de Nutrição em duas das mais expressivas bases de dados internacionais: a Scopus, em 2007, e a Web of Science (ISI/Thomson-Reuters), em 2008.

Esta primeira parte da Seção Temática sobre Métodos da Pesquisa em Nutrição apresenta ao leitor três trabalhos que expõem os caminhos investigativos de distintas subáreas do conhecimento em Nutrição.

No artigo Proposta metodológica para o módulo de consumo alimentar individual na pesquisa brasileira de orçamentos familiares - POF, Edna M. Yokoo e colaboradoras descrevem as etapas da metodologia utilizada para a estimativa de consumo da POF 2008/2009. A importância desse tipo de investigação reside no fato de que o único estudo nacional de consumo direto foi realizado 30 anos atrás, em 1974-75 (Estudo Nacional da Despesa Familiar - ENDEF). Assim, as informações sobre o consumo alimentar a serem coletadas pela POF 2008/2009 facultarão um maior conhecimento a respeito da situação nutricional das famílias brasileiras. Além disso, sabe-se da dificuldade de realização de inquéritos dietéticos populacionais, por sua complexidade e seu elevado custo7, e a publicação de um estudo sobre esses métodos servirá de suporte para futuras investidas da mesma natureza.

Em outra linha, as autoras Dulcineia S.P. Abdalla e Karine C.M. Sena, no trabalho Biomarcadores de peroxidação lipídica na aterosclerose, relacionam as técnicas de análise da oxidação de lipoproteínas e os distintos métodos envolvidos na adoção de biomarcadores para o estudo da aterosclerose. Chamam atenção, ainda, para a necessidade de escolha criteriosa do método que mais se ajuste ao tipo de pergunta a que se quer responder. O monitoramento desses indicadores se põe como ferramenta de grande valia para o processo de prevenção de doenças crônicas.

Finalmente, no terceiro artigo, Nutrição no pós-genoma: fundamentos e aplicações de ferramentas ômicas, de autoria de Eliane Fialho, Fernando S. Moreno e Thomas P. Ong, são definidos os principais tipos de técnica que vêm sendo adotados em uma nova frente aberta à pesquisa em Nutrição, qual seja a dos estudos do campo da genômica. De caráter inovador, a nutrigenômica está centrada na investigação da interação gene-nutriente. A possibilidade de utilização dessa técnica na investigação nutricional marca mais um avanço na identificação de biomarcadores para subsidiar o estabelecimento de recomendações dietéticas específicas para a prevenção de doenças.

As repercussões do I Seminário de Métodos na Pós-Graduação em Nutrição projetam desdobramentos positivos. Assim, no próximo Congresso Nacional de Nutrição da SBAN, em 2009, será realizado o II Seminário de Métodos na Pós-Graduação em Nutrição, dando continuidade aos planos de fortalecimento técnico do conhecimento produzido no bojo dos Programas de Pós-Graduação em Nutrição.

Para o próximo fascículo da Revista (Rev Nutr. v.22, n.1, jan./fev., 2009), já estão aprovadas mais três comunicações sobre diferentes métodos da pesquisa em nutrição, que concluirão esse panorama temático. São elas: Studying the Central Control of Food Intake and Obesity in Rat, de Eliane B. Ribeiro; Pesquisas Qualitativas em Nutrição e Alimentação, de Ana M. Canesqui; e Avaliação do impacto de programas nutricionais, de Iná S. Santos.

Com a publicação desses resultados do I Seminário de Métodos na Pós-Graduação em Nutrição em duas Seções Temáticas, a Revista de Nutrição espera contribuir para o avanço do conhecimento em Nutrição em suas diversas subáreas, ratificando a sua política editorial comprometida com o rigor científico e reconhecida por seus pares. 


\section{REFERÊ NCIAS}

1. Medeiros MAT. Revista de Nutrição inaugura seção temática [editorial]. Rev Nutr. 2006; 19(6):653-4.

2. Kac G, Fialho E, Santos SMC. Panorama atual dos programas de pós-graduação em Nutrição no Brasil. Rev Nutr. 2006; 19(6):785-92.

3. Kac G, Fialho E, Santos SMC, Assis AMO. Reflexões do I fórum de coordenadores de programas de pós-graduação em nutrição no Brasil. Rev Nutr. 2006; 19(6):771-84.

4. Castro RM, Osório M, Leandro CG, Kac G. II fórum de coordenadores de programas de pós-graduação em Nutrição no Brasil [editorial]. Rev Bras Saúde Matern Infant. 2007; 7(3):235-6.

5. Vasconcelos FAG. Tendências históricas dos estudos dietéticos no Brasil. Hist Cienc Saude-Manguinhos. 2007; 14(1):197-219.

6. Vasconcelos FAG. Combate à fome no Brasil: uma análise histórica de Vargas a Lula. Rev Nutr. 2005; 18(4):439-57.

7. Fisberg RM, Colucci AC, Morimoto JM, Marchioni DML. Questionário de freqüência alimentar para adultos com base em estudo populacional. Rev Saúde Pública. 2008; 42(3):550-4.

Maria Angélica Tavares de Medeiros

Editora Científica

Gilberto Kac

Coordenador do Fórum de Programas de Pós-Graduação em Nutrição 